\section{Occurrence and antimicrobial susceptibility of Salmonella isolates from grilled chicken meat sold at retail outlets in Erbil City, Kurdistan region, Iraq}

\author{
Dhary A. Almashhadany \\ Department of Pathological Analysis, \\ Knowledge University, Erbil, Kurdistan \\ Region, Iraq
}

\begin{abstract}
Food borne salmonellosis is a major public health problem worldwide. This study aimed to detect the occurrence and antibiotics sensitivity of Salmonella species in grilled chicken meat sold at retail outlets in Erbil City, Kurdistan, Iraq. Two hundred and twenty-five (225) samples were aseptically collected from central and suburb retail outlets. For isolation of salmonellae, samples were cultured on selective media and tested for their susceptibility to common antibiotics by disk diffusion assay. The results revealed that the overall prevalence of Salmonella among grilled chicken meat samples was $7.1 \%$. The isolates belonged to eight different serotypes of Salmonella. These include $S$. Typhimurium, $S$. Tennessee, $S$. Newport, $S$. Enteritidis, $S$. Anatum, $S$. Arizona, $S$. Muenchen, and $S$. Montevideo. The antibiotic resistance profile revealed a total resistance to Levofloxacin and total sensitivity to Cefotaxime, Amoxicillin, and Cefadroxil. This resistance among Salmonella may pose a public health hazard that requires effective precautions and response.
\end{abstract}

\section{Introduction}

Salmonella genus is one of the most significant food poisoning agents all over the world. The pathogenic potential of Salmonella was recognized in 1885 in pigs by two American pioneer scientists; Daniel E. Salmon and Theobald Smith (de Freitas Neto et al., 2010; Octavia \& Lan, 2014). Salmonella is a ubiquitous bacterium that can survive several weeks in a dry environment and several months in water. Within only two species ( $S$. enterica and $S$. bongori), more than 2,600 serotypes of Salmonella are dispersed in nature and often found in the intestinal tract of a wide range of mammalian hosts including humans, animals, and also found in birds. For practical purposes, Salmonella is generally classified into two categories; the first category is Typhoidal salmonellae, which include strains causing typhoid fever (TF) or paratyphoid fever (Salmonella Typhi, Paratyphi A, Paratyphi B, and Paratyphi C). These strains are carried only by humans. The second category called Non-typhoidal salmonellae (NTS), which include all other Salmonella strains. Non-typhoidal Salmonella is the most common and is an important cause of food poisoning. Strains of this category are carried by humans, different types of animals, poultry, wild birds, and flies (Octavia \& Lan, 2014).

Salmonellosis in human is a serious foodborne disease (FBD). Globally, it is estimated that the annual deaths by salmonellosis reach 500,000 and the incidence rate of non-typhoidal Salmonella gastroenteritis is 94 million cases, with approximately $85 \%$ of foodborne cases (WHO, 2018). Indeed, the World Health Organization (WHO) declared that FBDs is a major public health problem that increased in the last decade in both developed and developing countries (Ullah et al., 2019; WHO, 2008). Salmonellosis is most common in children and reaches its peak during summer and fall (Katiyo et al., 2019). Contaminated ready-to-eat food and fast food are a major source for human salmonellosis (WHO, 2008, 2018). Such contamination may occur during food processing, due to poor hygienic conditions of raw materials, or during handling characterized by poor hygiene (Adesetan et al., 2017; Bukar et al., 2010). The sources of contamination vary greatly but are mostly represented by fecal material from livestock, pets, birds, reptiles, asymptomatic human carriers (Abd El-Aziz, 2013; de Freitas Neto et al., 2010). Recently, there have been several salmonellosis cases linked to consumption of raw fruits and vegetables contaminated by manure from farmhouses or by insect vectors (Barreiro et al., 2013; Eni et al., 2010; de Freitas Neto et al., 2010). Despite the fact that freezing of meat greatly reduces viability of food borne pathogens, Salmonella tend to tolerate low temperature for long periods of time (Almashhadany, 2008; Shafini et al., 2017).

In Kurdistan region (Iraq), grilled chicken meats are most commonly served in food outlets especially in restaurants, retail outlets, street vendors, hotels, schools, canteens and even small outlets which involved different styles of preparations. Therefore, the aim of the study was to determine the occurrence and antimicrobial resistance of Salmonella among grilled chicken meats sold at retail outlets in Erbil City.
Correspondence: Dhary Alewy Almashhadany, Department of Pathological Analysis, Knowledge University, College of Science, Kirkuk, Erbil, Kurdistan Region, Iraq.

Tel.: +9647733565479

E-mail: dhary.hammed@knowledge.edu.krd

Key words: Salmonella, Serotyping, Kurdistan region, Antibiotics resistance.

Conflict of interest: the author declares no potential conflict of interest.

Funding: this study was supported by Knowledge University

Received for publication: 14 April 2019.

Revision received: 26 May 2019.

Accepted for publication: 27 May 2019

This work is licensed under a Creative Commons Attribution-NonCommercial 4.0 International License (CC BY-NC 4.0).

(C) Copyright D.A. Almashhadany, 2019 Licensee PAGEPress, Italy

Italian Journal of Food Safety 2019; 8:8233 doi:10.4081/ijfs.2019.8233

\section{Materials and Methods}

\section{Study design and sampling}

A total of 225 grilled chicken meat samples (75 Shawarma, 75 Thigh, and 75 Breast) were collected under sterile hygienic conditions during July to December 2018 in Erbil city according to previously published method (Sharaf and Sabra, 2012). One hundred eighteen (118) samples were collected from retail outlets at city center, whereas 107 samples were obtained from city outskirts.

\section{Isolation and identification of Salmonella}

Isolation procedures were carried out according to WHO enrichment method (WHO, 2010). Briefly, $10 \mathrm{~g}$ of each sample were added to $90 \mathrm{ml}$ of Buffered peptone water (Oxoid, UK) and incubated at $37^{\circ} \mathrm{C}$ for $24 \mathrm{~h}$ in ambient air. One $\mathrm{mL}$ of this culture was inoculated into Tetrathionate broth $(9 \mathrm{~mL})$ and incubated aerobically at $37^{\circ} \mathrm{C}$. After $24 \mathrm{~h}$, a loopful of broth was streaked on Brilliant Green Agar (BGA) and Xylose Lysine Deoxycholate agar (XLD) plates (Oxoid, UK) and aerobically incubated at $37^{\circ} \mathrm{C}$ for $24-48 \mathrm{~h}$. Colonies suspected to belong to Salmonella were picked and submitted for biochemical tests according to Todar (2012) and Strockbine and colleagues (2015). 


\section{Serotyping of isolates}

Serotyping of the isolates was carried out by slide agglutination using Remel ${ }^{\mathbb{B}}$ kit according to manufacturer instructions (Remel Europe Ltd., UK).

\section{Antibiotics susceptibility testing}

Disk diffusion assay on Mueller-Hinton agar (Oxoid, UK) was employed to evaluate the susceptibility of Salmonella isolates to a panel of ten commonly used antibiotics (Mast diagnostics, UK). The guidelines of CLSI were followed to perform the Modified Kirby-Bauer method and to interpret the inhibition zones diameters around antibiotic disks (CLSI, 2015). The following antimicrobials were tested: amikacin $\left(\mathrm{AK}_{10}\right), \quad$ amoxicillin/Clavulanic acid $\left(\mathrm{AMC}_{30}\right)$, cefadroxil $\left(\mathrm{CFR}_{30}\right)$, cefotaxime $\left(\mathrm{CTX}_{30}\right)$, imipenem (IMP $\left.{ }_{10}\right)$, kanamycin $\left(\mathrm{KAN}_{30}\right)$, levofloxacin $\left(\mathrm{LEV}_{5}\right)$, streptomycin $\left(\mathrm{STR}_{10}\right)$, and tetracycline $\left(\mathrm{TEC}_{30}\right)$.

\section{Statistical analysis}

Data were analyzed using SPSS software version 21. Confidence intervals are exact Clopper-Pearson confidence intervals. Two-sample proportion test was used to assess the difference in prevalence of Salmonella between city center and suburbs. Alpha level was set to 0.05 . Association between seasons and prevalence was calculated by Fisher's exact test.

\section{Results}

Out of 225 grilled chicken meat samples, $16(7.1 \%)$ were positive for the presence of Salmonella. Of note, 9.3\% of thigh samples harbored Salmonella. The distribution of positive samples is summarized in Table 1. Statistically, it is estimated that $4.12-11.29 \%$ (95\% confidence interval) of grilled chicken meat in Erbil retail outlets are contaminated by Salmonella species.

Grilled chicken meat samples from city center showed less contamination rate $(5.9 \%)$ in comparison to suburbs samples $(8.4 \%)$. Despite the apparent difference in prevalence between samples from city center and those from outskirts, the difference between the two groups is not statistically significant $\left(Z_{c}=0.72 ; P=0.471\right)$. On the contrary, summer months (July and August) were significantly associated with increase in Salmonella prevalence $(\mathrm{P}=0.033)$ (Table 2). Regarding Salmonella serotypes, sixteen isolates belonged to eight different serotypes. $S$. Typhimurium and $S$. Anatum were the most commonly detected serotypes (25\% and $19 \%$, respectively), while other detected serotypes and their iso- lation rate are summarized in Figure 1.

Salmonella isolates were tested against ten commonly used antibiotics. The results of susceptibility testing are depicted graphically in Figure 2. Strikingly, penicillins and cephalosporins antibiotics showed a good activity against isolated salmonellae, while higher number of resistant strains were observed to tested aminoglycosides and levofloxacin and imipenem.

\section{Discussion}

Salmonellosis is a major cause of human bacterial gastroenteritis thatrepresents a growing public health concern in both developing and developed countries. It has been declared by the Food Agriculture Organization (FAO) and the Pan American Health Organization (PAHO) as the most common and significant foodborne disease since 1950 (FAO \& PAHO, 2017). In the present study, the prevalence of Salmonella in grilled chicken meat samples was $16 / 225(7.1 \%, \mathrm{CI} ; 4.12 \%$ $11.29 \%$ ) (Table 1). These results are consistent with an Egyptian study in Luxor city which found that the isolation rate of Salmonella in ready-to-eat meat (RTE) samples was $6.67 \%$ (Younis et al., 2019). However, a slightly lower rates were reported in Bangladesh (5\%) and in Egypt (4.4\%) where Salmonella prevalence in street food was $5 \%$ (Abd- El-Malek, 2017; Khalif et al., 2018). In contrast, higher rates where reported from Korea (22.4\%), Australia (38.8\%), and China (54\%) (Kim et al.,
2012; Fearnley et al., 2011; Yang et al., 2010). Such variations may be attributed to difference in geographical location, season, sanitation practices, and laboratory detection methods (Lee et al., 2015). A higher proportion of contaminated chicken meat samples was found in suburb areas $(9.3 \%)$. This may be a direct result of exposure to many potential contaminating sources (such as farms, waste treatment facilities, wild animals) existing in the outskirts of cities. In community-based studies, FAO \& WHO found a link between the increase prevalence of Salmonella in poultry and increase of human salmonellosis cases (WHO, 2018). Consequently, reducing poultry contamination would reduce salmonellosis in human.

In terms of detected serotypes, various reports showed different serotypes to be the most common. However, S. Typhimurium and $S$. Enteritidis tend to have the highest prevalence in different regions. For instance, a Korean study found $\mathrm{S}$. Enteritidis to be the dominant serovar (57\%). Furthermore, a recent Egyptian study found $S$. Typhimurium and $S$. Enteritidis serovars to constitute $62.5 \%$ of detected salmonellae in ready-to-eat meat samples (Younis et al., 2019). It is wellknown that ecological distribution of Salmonella serovars are subjected to various environmental factors (Chousalkar \& Gole, 2016).

Regarding Salmonella serovars isolated in this study (Figure 1), S. Typhimurium was the most prevalent $(25.0 \%)$ which is in good agreement with the results obtained in reports from Egypt (25\%) and China

Table 1. Occurrence of Salmonella among grilled chicken meat samples.

\begin{tabular}{lccc} 
Collection site & No. examined & No. positive (\%) & $95 \%$ CI \\
Shawarma & 75 & $4(5.3)$ & $1.47-13.10$ \\
Thigh & 75 & $7(9.3)$ & $3.84-18.29$ \\
\hline Breast & 75 & $5(6.7)$ & $2.20-14.88$ \\
Total & 225 & $16(7.1)$ & $4.12-11.29$ \\
\hline
\end{tabular}

Table 2. Prevalence of Salmonella among grilled chicken meat during study period.

\begin{tabular}{lccccc} 
Month & $\begin{array}{c}\text { No. of examined (no. of positive) } \\
\text { Shawarma }\end{array}$ & Thigh & Breast & $\begin{array}{c}\text { Total examined } \\
\text { (total positive) }\end{array}$ & $\%(95 \%$ CI) \\
July & $12(1)$ & $12(2)$ & $12(1)$ & $36(4)$ & $11.1(3.11-26.06)$ \\
August & $12(2)$ & $12(3)$ & $13(2)$ & $37(7)$ & $18.4(7.74-34.33)$ \\
\hline September & $13(1)$ & $12(1)$ & $12(1)$ & $37(3)$ & $8.1(1.7-21.91)$ \\
October & $13(0)$ & $13(1)$ & $13(1)$ & $39(2)$ & $5.1(0.63-17.32)$ \\
\hline November & $12(0)$ & $13(0)$ & $13(0)$ & $38(0)$ & $0(0.00-9.49)$ \\
December & $13(0)$ & $12(0)$ & $12(0)$ & $37(0)$ & $0(0.00-9.25)$ \\
\hline Total & $75(4)$ & $75(7)$ & $75(5)$ & $225(16)$ & $7.1(4.12-11.29)$ \\
\hline
\end{tabular}


(27.6\% for $S$. Typhimurium and $S$. Enteritidis) (Yang et al., 2010; Younis et al., 2019). On the contrary, lower prevalence of salmonellae in chicken meat samples was documented in other reports from Brazil and Egypt ranging from $4 \%$ to $5 \%$ (Giombelli \& Gloria, 2014; Shaltout et al., 2013). Antibiotics resistance in Salmonella is increasing constantly. Surveillance reports demonstrated a two-fold increase in Salmonella resistant phenotypes (from $20 \%-30 \%$ to ca. $70 \%$ ) since early 1990 s to 2000s (Su et al., 2004). In this study, an intriguing observation is the complete resistance to levofloxacin Figure 2). In general, fluoroquinolones resistance mechanisms in Salmonella can be mediated by point mutations that protect DNA gyrases or efflux pumps that extrude antibiotics out of the bacterial cell or plasmid mediated resistance determinants (Eng et al., 2015). The latter is of public health importance due to its inter-species potential spread. Development of such high level of fluoroquinolones resistance in Salmonella is usually rare (CDC, 2010). This observation is a serious alarm owing to the fact that fluoroquinolones are central drugs in treatment of sever human salmonellosis.

Indeed, increase use of antibiotics in food animals' industry for therapeutic, prophylactic, and growth promoting purposes increases and selects for resistant phenotypes for employed antibiotics. Unfortunately, to the best of our knowledge, the status of usage of fluoroquinolones in poultry and resistance rate in Iraq are still unknown. Recently, multidrug resistant salmonella isolates were recovered from poultry meat samples and showed resistance to streptomycin $(30.9 \%)$, tetracycline $(13.9 \%)$, gentamicin (12.6\%) (Liljebjelke et al., 2017). However, the susceptibility pattern to ceftriaxone ( $75 \%$ resistant) was higher than the findings of the current study $(12.5 \%)$. A close rate of ceftriaxone resistance $(16 \%)$ was found in a large Chinese study (Yang et al., 2010). Additionally, recent report from Pakistan Kohat district found salmonellae resistant to ampicillin $(80 \%)$, tetracycline $(78 \%)$, and poor efficacy of fluoroquinolones (ciprofloxacin and levofloxacin) (Ullah et al., 2019).

Generally, resistance to carbapenems, including imipenem, in Enterobacteriaceae is usually mediated by either decreased outer membrane permeability (loss/modification of porins channels) or by carbapenems-hydrolyzing enzymes (best reviewed in Nordmann et al., 2012). Carbapenemases are three different types of $\beta$-lactamases, designated as Amber classes (A, B, \& C). These enzymes are either chromosomallyencoded or plasmid-mediated with poten- tials to be transferred between related bacterial species (Patel \& Bonomo, 2013). Imipenem resistance in Salmonella is very rare. However, a resistant clinical strain had been recovered in 2003 and found to harbor KPC-2 $\beta$-lactamase gene (Miriagou et al., 2003). Moreover, imipenem resistance in Salmonella has been reported to be conferred by both mechanisms (porin loss and $\beta$-lactamase) simultaneously (ArmandLefevre et al., 2003).

\section{Conclusions}

A slightly alarming prevalence of Salmonella in grilled chicken meat samples has been found in the present study. Salmonellosis is an important food borne disease that needs to be further investigated in Erbil city. The findings should be interpreted with caution due to small recovery rate and short study period. Recovery of different Salmonella serovars from chicken meat samples is of concern, especially because of their high resistance level to important antimicrobials. Epidemiological and molecular investigations should follow this previous study to assess the risk for consumers. Random antibiotics usage should be restricted to minimize public health hazards of spreading multi-drug resistance pathogens. A four-season study is recommended to further investigate the distribution of salmonellae isolates in various meat samples accompanied by antimicrobial susceptibility testing to reduce burden and morbidity of salmonellosis in Erbil city.

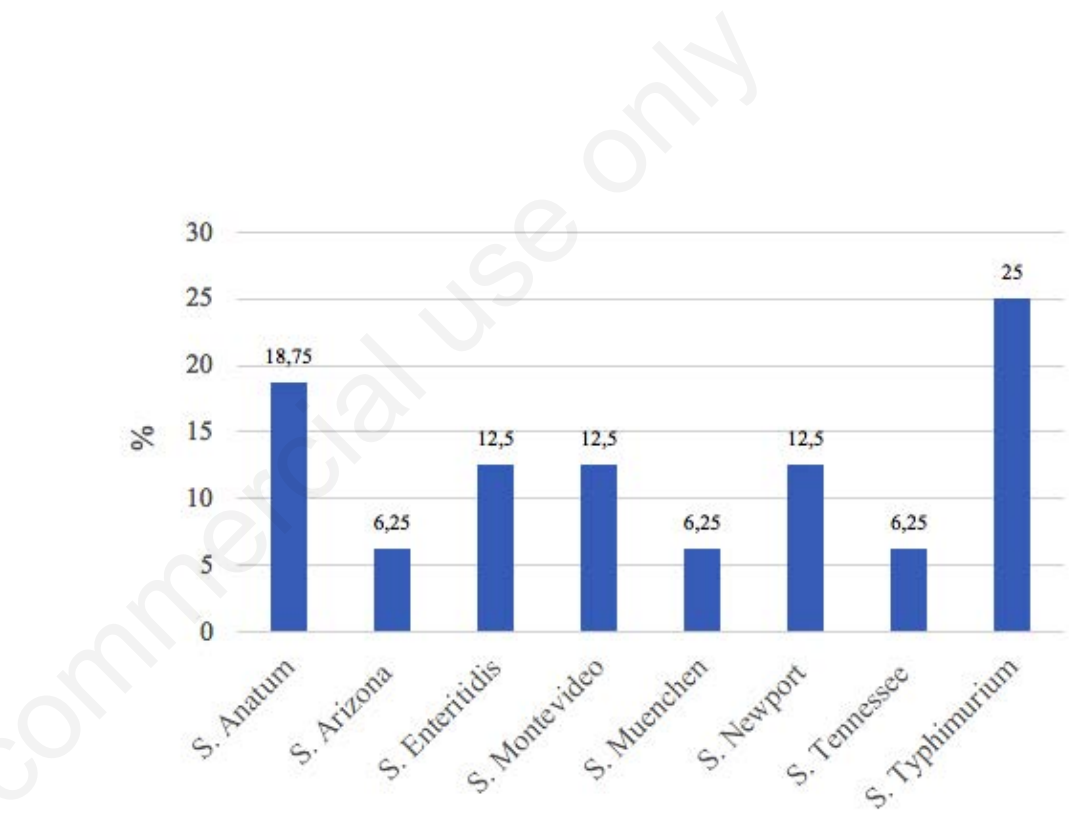

Figure 1. Percentage of different detected Salmonella serotypes in positive samples $(n=16)$.

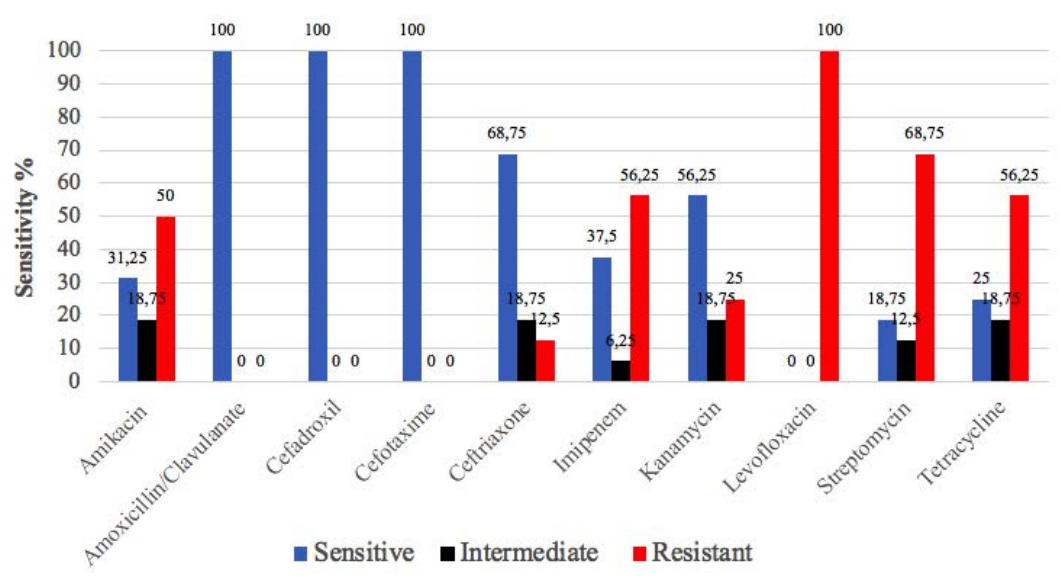

Figure 2. Antibiogram profile of Salmonella isolates from grilled chicken meat samples. 


\section{References}

Abd El-Aziz DM, 2013. Detection of Salmonella Typhimurium in retail chicken meat and chicken giblets. Asian Pac J Trop Biomed 3:678-81.

Abd-El-Malek AM, 2017. Cooked poultry meat and products as a potential source of some food poisoning bacteria. J Env Sci Toxicol Food Technol 11:23-9.

Adesetan TO, Mabekoje OO, Bello OO, 2017. Bacteriological quality of street vended ready-to-eat foods in AgoIwoye, Nigeria: A study of University environment. Int $\mathrm{J}$ Microbiol Res Rev 6:215-29.

Almashhadany DA, 2008. Hygienic Significance of Salmonella among Red Meat in Thamar City. Thamar Uni J 9:73-84.

Armand-Lefevre L, Leflon-Guibout V, Bredin J, Barguellil F, Amor A, Pages JM, Nicolas-Chanoine MH, 2003. Imipenem resistance in Salmonella enterica serovar Wien related to porin loss and CMY-4 $\beta$-lactamase production. Antimicrob Agents Chemother 47:1165-8

Barreiro C, Albano H, Silva J, Teixeira P, 2013. Role of Flies as Vectors of Foodborne Pathogens in Rural Areas. ISRN Microbiol 2013:718780.

Bukar A, Uba A, Oyeyi TI, 2010. Occurrence of Some Enteropathogenic Bacteria in Some Minimally and Fully Processed ready-to-eat foods in Kano metropolis, Nigeria. Afr J Food Sci 4:32-6.

CDC (The Centers for Disease Control and Prevention), 2010. National Antimicrobial Resistance Monitoring System for Enteric Bacteria (NARMS): Human isolates final report, 2008. Atlanta, GA. Available from: https://www.cdc.gov/narms/pdf/2013annual-report-narms-508c.pdf

Chousalkar K, Gole VC, 2016. Salmonellosis acquired from poultry. Curr Opin Infect Dis 29:514-9.

CLSI (Clinical Laboratory Standards Institute), 2011. Performance standards for antimicrobial disk susceptibility tests; document M2-A9. 26:1.

de Freitas Neto OC, Penha FR, Barrow P, Berchieri JA, 2010. Sources of human non-typhoid salmonellosis: a review. Brazilian J Poult Sci 12:1-11.

Duc VM, Nakamoto Y, Fujiwara A, Toyofuku H, Obi T, Chuma T, 2019. Prevalence of Salmonella in broiler chickens in Kagoshima, Japan in 2009 to 2012 and the relationship between serovars changing and antimicrobial resistance. BMC Vet Res 15:108.
Eng SK, Pusparajah P, Ab Mutalib NS, Ser HL, Chan KG, Lee LH, 2015. Salmonella: a review on pathogenesis, epidemiology and antibiotic resistance. Front Life Sci 8:284-93.

Eni AO, Oluwawemitan IA, Solomon OU, 2010. Microbial quality of fruits and vegetables sold in Sango Ota, Nigeria. Afr J Food Sci 4:291-6.

FAO, PAHO (Food and Agriculture Organization and Pan American Health Organization), 2017. Food Handlers Manual. Instructor. Washington, DC.

Fearnley E, Raupach J, Lagala F, Cameron $\mathrm{S}, 2011$. Salmonella in chicken meat, eggs and humans; Adelaide, South Australia, 2008. Int J Food Microbiol 146:219-27.

Giombelli A, Gloria MB, 2014. Prevalence of Salmonella and Campylobacter on broiler chickens from farm to slaughter and efficiency of methods to remove visible fecal contamination. J Food Prot 77:1851-9.

Katiyo S, Muller-Pebody B, Minaji M, Powell D, Johnson AP, De Pinna ED, Day M, Harris R, Godbole G, 2019. Epidemiology and Outcomes of Nontyphoidal Salmonella Bacteremias from England, 2004 to 2015. J Clin Microbiol 57:e01189-18.

Khalif MA, Hossain K, Rumi NA, Rahman S, Hosen A, 2018. Identification and antibiogram study of bacteria isolated from different street food. Asian J Med Biol Res 4:279-87.

Kim MS, Lim TH, Jang JH, Lee DH, Kim BY, Kwon JH, Choi SW, Noh JY, Hong YH, Lee SB, Yang SY, Lee HJ, Lee JB, Park SY, Choi IS, Song CS, 2012. Prevalence and antimicrobial resistance of Salmonella species isolated from chicken meats produced by different integrated broiler operations in Korea. Poult Sci 91:2370-5.

Lee KM, Runyon M, Herrman TJ, Phillips R, Hsieh J, 2015. Review of Salmonella detection and identification methods: aspects of rapid emergency response and food safety. Food Control 47:26476.

Liljebjelke KA, Hofacre CL, White DG, Ayers S, Lee MD, Maurer JJ, 2017. Diversity of antimicrobial resistance phenotypes in Salmonella isolated from commercial poultry farms. Front Vet Sci 4:96.

Miriagou V, Tzouvelekis LS, Rossiter S, Tzelepi E, Angulo FJ, Whichard JM, 2003 Imipenem resistance in a Salmonella clinical strain due to plasmid-mediated class A carbapenemase KPC-2. Antimicrob Agents Chemother 47:1297-300.
Nordmann P, Dortet L, Poirel L, 2012. Carbapenem resistance in Enterobacteriaceae: here is the storm!. Trends Mol Med 18:263-72.

Octavia S, Lan R, 2014. The family Enterobacteriaceae. In: Rosenberg E, Delong EF, Lory S, Stackebrandt E, Thompson F, eds. The ProkaryotesGammaproteobacteria $4^{\text {th }}$ edn. Vol 6, Springer, Heidelberg. pp 225-286.

Patel G, Bonomo R, 2013. Stormy waters ahead: global emergence of carbapenemases. Front Microbiol 4:48.

Shafini AB, Son R, Mahyudin NA, Rukayadi Y, Tuan Zainazor TC, 2017. Prevalence of Salmonella spp. in chicken and beef from retail outlets in Malaysia. Int Food Res J 24:437-49.

Shaltout FA, Amani M, Mahmoud AH, AbdElraheem KA, 2013. Bacterial Aspect of Cooked Meat and Edible Offal at Street Vendors Level. Benha Vet Med J 24:320-8.

Sharaf EM, Sabra SM, 2012. Microbiological loads for some types of cooked chicken meat products at AlTaif governorate, KSA. World Appl Sci J 17:593-7.

Strockbine NA, Bopp CA, Fields PI, Kaper JB, Nataro JP, 2015 Escherichia, Shigella, and Salmonella. In: Jorgensen $\mathrm{JH}$, \& Pfaller MA, eds. Manual of Clinical Microbiology 11th edn, ASM press, Washington DC. pp 685-713.

Su LH, Chiu CH, Chu C Ou JT, 2004. Antimicrobial resistance in nontyphoid Salmonella serotypes: a global challenge. Clin Infect Dis 39:546-51.

Todar K, 2012. Salmonella and Salmonellosis. University of Wisconsin-Madison, Department of Bacteriology. Todar online Textbook of Bacteriology. Available form: www.textbookofbacteriology.net

Ullah I, Khattak NM, Khan Z, Rehman H, Naveed H, Shuja MN, Naeem M, MatiullahUllah I, Rehman HU, 2019. Isolation, identification and antibiotic susceptibility pattern of Salmonella species isolated from poultry samples of District Kohat. Int J Biosci 14:284-92.

WHO (World Health Organization), 2008. Foodborne disease outbreaks: Guidelines for investigation and control. ISBN 978924154722 2. NLM classification: WC 260.

WHO (World Health Organization), 2010. Laboratory Protocol Isolation of Salmonella spp. 5th Ed. From Food and Animal Faeces. WHO Global Foodborne Infections Network (formerly WHO Global Salm - Surv):1-18.

WHO (World Health Organization), 2018. Salmonella (non-typhoidal). Available 
from: https://www.who.int/newsroom/fact-sheets/detail/salmonella(non-typhoidal). Accessed on 12.04.2019.

Yang B, Qu D, Zhang X, Shen J, Cui S, Shi
Y, Xi M, Sheng M, Zhi S, Meng J, 2010. Prevalence and characterization of Salmonella serovars in retail meats of marketplace in Shaanxi, China. Int J Food Microbiol 141:63-72.
Younis RI, Nasef SA, Salem WM, 2019. Detection of multi-drug resistant foodborne bacteria in ready-to-eat meat products in Luxor city, Egypt. Int J Vet Sci 2:20-35. 